\title{
DEVELOPMENT AND VALIDATION OF A MULTIMEDIA PACKAGE FOR TEACHING APPLIED ELECTRICAL AND ELECTRONIC COMPONENT OF BASIC TECHNOLOGY
}

\author{
Mustapha Sani Sumaila ${ }^{1}$, H. Bello ${ }^{2}$, and A. S. Okegbile ${ }^{3}$ \\ ${ }^{1}$ School of Secondary Education (Technical) Federal College of Education (Technical) Bichi, Kano State, Nigeria \\ ${ }^{2}$ Faculty of Technology Education Abubakar Tafawa Balewa University, Bauchi, Nigeria \\ ${ }^{3}$ School of General Education Federal College of Education (Technical) Bichi,Kano State, Nigeria \\ E-mail:mustphasani@gmail.com
}

\begin{abstract}
This study developed and validated a multimedia package for the teaching of Electrical/Electronic component of Basic Technology at the upper basic education level. It was a developmental research design. The area for this study is Kano state, North-Western Nigeria. The population consists of 291 Basic Technology teachers, out of this, 10 Basic Technology teachers, 5 instructional technologist and 5 computer specialists were purposely selected for the product evaluation based on four instruments. The findings revealed that design procedures were followed in the development of the Electricity/Electronics component of Basic Technology Instructional Package (EECOBTIP); EECOBTIP have adequately covered the curriculum content of the subject matter; EECOBTIP have met required instructional technology standards; and EECOBTIP have met the required technical standards. The study therefore recommends amongst others that Basic Technology teachers should be encouraged to prepare some aspects of their lessons in electronic form; EECOBTIP should be utilized for classroom instruction especially when teaching the Electricity/Electronics component of Basic Technology; and that similar packages should be developed for the other aspects of Basic Technology curriculum.
\end{abstract}

Keywords: basic technology, development and validation, electrical/electronic, multimedia package

\section{INTRODUCTION}

The design and development of an instructional package for teaching and learning is an instructional design process. According to Tennyson [1], the roots of instructional theory can be traced to early efforts by educational psychologists to develop a connection between the science of psychology and the practical application of learning theory in educational settings. Two theorists of particular importance at the turn of the century were Dewey [2], who envisioned a special linking science between learning theory and educational practice, and Thorndike [3], who investigated principles of learning that could be directly applied to the teaching process (i.e., the laws of effect and exercise). He developed a body of instructional design principles that included task analysis and teaching methods based on his research findings and student evaluation methods [3].

Basic Technology is among the core subjects taught at the Basic Education level of Nigeria's curriculum, and according to Adeoye \& Olabiyi [4], it is also meant to provide basic knowledge about industrial technology. It is designed to develop in students an appreciation of technology and an interest in specific areas of industrial technology. On completion of junior secondary school, students are streamed into: (i) senior secondary school; (ii) technical college; (iii) an out-of-school vocational training center; and (iv) an apprenticeship scheme. This is based on results from the Junior Secondary School Certificate 
Examination (JSSCE), whose purpose is to determine their academic ability, aptitude and vocational interests [5].

The curriculum used to teach the subject (Basic Technology) was developed by various subject specialists and Applied Electricity and Electronics is among the nine thematic areas of the subject. This component of Basic Technology is aimed at introducing the learner to the basic concepts and devices in electricity/electronic technology. It therefore formed the foundation upon which the inculcation of basic knowledge and scientific skills in electronics, which is one of the objectives of technical education as stated in the National Policy on Education [5], is laid.

The development and use of electronic learning materials, have, in recent years, provided access to knowledge through multiple modes of learning. Several attempts are being made by governments to ensure the success of the UBE scheme as well as the actualization of the stated goals. The establishment of the Universal Basic Education Commission (UBEC) and State Universal Basic Education Board (SUBEB) at the Federal and state levels respectively with the mandate to regulate, control, and manage basic education institutions in the country are some of the bold steps taken in that direction. The key organizations in delivering UBE are the school, personnel (teaching and non-teaching) as well as adequate and relevant learning resources. Research and discourse in education in the country is often lopsided towards aspects of teacher quantity and quality, resources availability, funding and supervision at the expense of developmental research [6]-[8]. In the same vein, there is strong paradigm shift from the traditional teacher centered approach to a learner centered and ICT driven learning approaches [9]-[16].
The world is moving away from the traditional approach to teaching and learning. There is the widespread use of modern teaching and learning approaches. This involves a paradigm shift that has fundamentally changed the way in which teachers can now teach and how learners can now learn more efficiently and far more effectively. The transition to this new paradigm presents a considerable challenge on how to transform teaching and learning practices that have been in place for the last several hundred years [17]. This paradigm shift involves the use of an electronic learning package. Electronic learning media facilitate students to be understand and comprehend certain contents of engineering subjects [18]. These are approaches that will very much address the inadequacies of Nigeria's peculiar situations of overcrowded classrooms, obsolete and outdated equipment, erratic power supplies, and absence of state of the art teaching/learning resources [19]. Similarly, learning materials are drastically in short supply in public schools. For example, in 2005/06 one textbook was shared among four public primary school students; nineteen junior secondary school students; and sixteen senior secondary school students respectively [20]. This will pose challenges to the current teaching approaches, that is, the traditional chalk and board methods. It is with a view to address these issues that this research work was undertaken.

The main purpose of the study was to develop and validate a multimedia package for the teaching of Electrical/Electronic component of Basic Technology. Specifically, the study: (1) develop and build an Electricity/Electronics component of Basic Technology Instructional Package (EECOBTIP) for teaching Basic Technology at Upper Basic Education level, (2) establish 
whether the subject matter content of EECOBTIP cover the required areas of Basic Electronics Device syllabus in appropriate and sequential manner, (3) find out the assessment of the Instructional Technologist about EECOBTIP in meeting instructional design requirements, (4) find out the assessment of the Computer Specialist about EECOBTIP in meeting technical requirements.

\section{METHOD}

The design and development processes consist of a design and development of a Learning Object. It is a developmental research. Developmental research is the systematic study of designing, developing, and evaluating instructional programs, processes, and products that must meet criteria of internal consistency and effectiveness [22]. Developmental research is particularly important in the field of instructional technology. The most common types of developmental research involve situations in which the product development process is analyzed and described, and the final product is evaluated [23]. A learning object is any grouping of materials that is structured in a meaningful way and is tied to an educational objective [24]. The materials in a learning object can be documents, pictures, simulations, movies, sounds, and so on. Structuring these in a meaningful way implies that the materials are related and are arranged in a logical order. But without a clear and measurable educational objective, the collection remains just a collection [25].

For this stage, data collection took the following form: (1) Documentation of the design, development, and evaluation tasks, including profiling the design and development context and collecting data work time and expenses, problems encountered and decisions made, adjustments made in the original plans, designer reactions and attitudes, or records of concurrent work patterns; (2) Documentation of the conditions under which the development and implementation took place, including factors such as equipment and resources available, participant expertise and background, or time and client constraints; and (3) Identifying the results of pre-design needs assessments, formative, summative and confirmative evaluations, including documentation of the target populations and the implementation context, and measures of learning, transfer, and the impact of the package on teaching or learning.

The second stage was the validation stage where the designed and developed package was validated. An expert assessment survey was conducted. The product was subjected to evaluation by Basic Technology Teachers, Instructional Technologists and Computer Specialists from some selected Colleges of Education and the Kano Educational Resource Department. At the end of the study, therefore, EECOBTIP was produced.

The area for this study was Kano state, North-Western Nigeria. Kano state lies within the Coordinates $11^{0} 30^{\prime} \mathrm{N} 8^{0} 30^{\prime} \mathrm{E}$. It boarders with Katsina state in the north/west; Jigawa state in the east; and Plateau and Kaduna states in the south.

The population for this study consists of 291 Basic Technology teachers from 869 secondary schools in Kano State. The schools were spread across 14 education zones under the Kano State Secondary Schools Management Board and 22 Technical Colleges under Kano State Science and Technical Schools Board.

For this study, 10 Basic Technology teachers, 5 instructional technologist and 5 computer specialists were purposely selected 
for the evaluation of the package based on the instrument for assessment. Purposive sample is a non-probality sampling which is used where sampling for proportionality is not the main concern [26].

In the Validation of EECOBTIP, expert(s) assessment survey was conducted for the purpose of validation of the Electricity/Electronics component of Basic Technology (EEITM). The package was subjected to evaluation by 5 Instructional Technologists from the Faculty of Technology Education, Abubakar Tafawa Balewa University, Bauchi; 5 Computer specialists from Federal College of Education (Technical) Bichi; and 10 Basic Technology teachers from the Kano State Ministry of Education. Three different instruments were used to determine the Validity and reliability of the developed package. They include (1) Basic Technology Teachers Assessment Rating Scale (BETTARS), (2) Instructional Technologist Assessment Rating Scale (ITARS), and (3) Computer Specialist Assessment Rating Scale (CSARS).

$$
\text { Basic Technology Teachers }
$$

Assessment Rating Scale (BETTARS) was the instrument developed by the researchers and was administered to 10 Basic Technology Teachers to ascertain the adequacy of the content of the Package with regards to the officially prescribed content of the 9-year Basic Education curriculum. The validity of the BETTARS was established by giving it out to experts in Basic Technology from the Kano State Educational Resources Department. The test-retest method was used to determine the reliability of the instrument. It was administered to ten Basic Technology Teachers, after an interval of two weeks, it was re-administered and a reliability coefficient $r$ was found to be 0.684653 . Instructional Technologist Assessment Rating Scale (ITARS) was given to 5
Instructional Technologists for the purpose of finding out whether it conforms to acceptable standards of Instructional development and delivery using the instrument. This instrument, in addition to demographic data, contains an adaption of items of the Learning Objects Review Instrument (LORI). The respondents were required to respond to statements and rate the adequacy and appropriate sequencing of the contents, appropriate language use among others. The validity of the ITARS was established by giving it out to experts in Instructional Technology from Federal College of Education (Technical) Bichi. The test-retest method was used to determine the reliability of the instrument. It was administered to five Instructional Technologists, after an interval of two weeks, it was re-administered and a reliability coefficient $\mathrm{r}$ was found to be 0.693375 .

Computer Specialist Assessment Rating Scale (CSARS) was an adoption of the Computer Expert Assessment Questionnaire (CEAQ) (Olawale, 2014), in addition to demographic data, it contains 15 structured items. The validity of the CSARS was established by giving it out to computer experts from Federal College of Education (Technical) Bichi. The test-retest method was used to determine the reliability of the instrument. It was administered to five Computer Specialists, after an interval of two weeks, it was re-administered and a reliability coefficient $r$ was found to be 0.818182 . It was administered to 5 Computer Analysts requesting them to rate the package about the typography, legibility, navigation, and the simulation properties among others, of the instructional package.

The returned instruments bring into focus the various opinions of the respective experts concerning the modifications required. These observations include the 
pictures; sounds and voice; video slide transition, contrast and colour as well as the general textual arrangement of the package. All the observed and suggested modifications were carefully executed before the final package was produced.

In determining the acceptance and/or rejection of mean, the means score of 3.00 was used so that any item that has a mean score of 3.00 and above was considered as adequate and accepted, while an item with mean score below 3.00 will be considered as inadequate and rejected.

\section{RESULTS AND DISCUSSION}

The content of the subject, that is, Electricity/Electronics component of Basic Technology, as specified by the Nigerian Educational Research and Development Council curriculum for Basic Technology [27] and the corresponding syllabus emanating from it, was drafted by the researchers using Microsoft Office Word. It was termed "Electricity/Electronics component of Basic Technology Instructional Treatment Manual (EEITM)". The draft was given to three experienced Basic Technology teachers for thorough scrutiny. This was to ensure that it adequately covered the topic. The input of the teachers was taken into consideration and the document was thoroughly revised. The EEITM provides an overview of the major content areas of Electricity/Electronics component of Basic Technology. It comprise of fourteen (14) lessons of five to fifteen minutes each.

The lessons recorded include: (1)Basic Emission, (2) Cold Cathode Devices, (3) Semiconductor Devices, (4) Diodes, (5) Resistorsand their classification, (6) Transistors Classification and Configuration, (7) Capacitors, (8) Functions/Uses of
Electronic Devices, (9) Transmission of Electricity, (10) Transmission of Electricity 2, (11) Transmission of Electricity 3, (12) Equipment used for the Transmission of Electricity, (13) Simple Electrical Wiring and (14) Simple Electrical Wiring 2.

The Microteaching Laboratory of Federal College of Education (Technical) Bichi was utilized for the recordings and final editing of the video recordings of the lessons. The final stage of the development process of the EEITM makes use of a personal computer, a laptop, a headphone, HD microphone, Geenee HD8001 Digital Visualizer, and a Geenee Spark Interactive Board. Other computer programs that were also utilized during the developmental process include Microsoft Word 2010 for texts and graphics; Macromedia Fireworks for specific texts and graphics; Microsoft Office power point for presentations and Microsoft Movie Maker for editing.

Table 1 presents the responses of 10 Basic Technology Teachers on the adequacy of the content of the Package with regards to the officially prescribed content of the 9-year Basic Education curriculum. Items 1 to 4 describes the personal data of the respondents, which indicates that they are Basic Technology teachers at Junior Secondary School level; $80 \%$ were male; their highest qualification was first degree; and most of them have been teaching the subject for more 10 years. Items 5 to 13 explored the adequacy of the package in covering the content of the curriculum for Basic Electronic Devices. The mean rating of the respondents indicate minimum mean rating of 4.40 and a maximum mean rating of 4.70. This shows that the respondents were satisfied with the adequacy of the package in covering the curriculum content of the subject. 
Similarly, a mean score of 4.60 and 4.50 for items 14 and 15 respectively shows that the respondents were satisfied with the adequacy of the package in the sequential arrangement of the sub-topicsto allow for transitional learning and that the Language used is comprehensive enough for students and teachers to understand. Also the mean scores of 4.60, 4.60 and 4.60 respectively for items 16, 17 and 18 indicates that the Basic Technology Teachers were satisfied with the adequacy of the package in ensuring that the objectives of the 9 year Basic Education curriculum in providing pre-vocational orientation for further training in technology; providing basic technological literacy for everyday living; and stimulating creativity were achieved. Finally, the mean scores of 4.60 and 4.50 for items 19 to 22 respectively shows that the respondents were satisfied with the adequacy of the package in ensuring that the practice exercises were relevant to the topics; the diagrams are clear enough and they have actually projected and explained what they are intended to explain; and the Package was well designed. This signifies the fact that based on the Nigerian Educational Research and Development Council curriculum the package have adequately covered the content especially as it affects the Electricity/Electronics component of Basic Technology.

Table 2 presents the responses of 5 Instructional Technologists for the purpose of finding out whether the package conforms to acceptable standards of Instructional development and delivery. Items 1 to 4 describes the personal data of the respondents, which indicates that three were from the University and two from a College of Education; they all possesses Ph.D and well experienced. The instrument used, that is, the Learning Object Review Instrument (LORI) enable reviewers (respondents) to rate or comment with respect to nine items. When used by a panel of reviewers, it is recommended that the convergent participation model for collaborative evaluation be [28].

The results were therefore presented as sets of average ratings, one per item. The rating ranges from 1 for low rating and 5 for high rating. Item 5 corresponds to item 1 of the LORI which rated the content Quality of the package. The respondents rated the veracity, accuracy, balance presentation of ideas and appropriate level of detail of the package. On this item, a mean rating of 4.0 was obtained, indicating a high rating in this regard. This shows that the content is free of error and presented without bias or omissions that could mislead learners. Claims are supported by evidence or logical argument. Presentations emphasize key points and significant ideas with an appropriate level of detail. Differences among cultural and ethnic groups are represented in a balanced and sensitive manner.

The results were therefore presented as sets of average ratings, one per item. The rating ranges from 1 for low rating and 5 for high rating. Item 5 corresponds to item 1 of the LORI which rated the content Quality of the package. The respondents rated the veracity, accuracy, balance presentation of ideas and appropriate level of detail of the package. On this item, a mean rating of 4.0 was obtained, indicating a high rating in this regard. This shows that the content is free of error and presented without bias or omissions that could mislead learners. Claims are supported by evidence or logical argument. Presentations emphasize key points and significant ideas with an appropriate level of detail. Differences among cultural and ethnic groups are represented in a balanced and sensitive manner. 
Item 6 , corresponding to item 2 on the LORI rated the Learning Goal Alignment of the Package. This item rated the alignment among learning goals, activities, assessment and learner characteristics. The mean rating of the respondents on this item was 3.80, which was acceptably high enough that is, Learning goals are declared, either within content accessed by the learner or in available metadata. The learning goals are appropriate for the intended learners. The learning activities, content and assessments provided by the object align with the declared goals. The learning object is sufficient in and of itself to enable learners to achieve the learning goals.

Table 1. Responses of Basic Technology Teachers on the Adequacy of the Content of the Package with Regards to the Officially Prescribed Content of the 9-Year Basic Education Curriculum

\begin{tabular}{|c|c|c|c|c|c|c|}
\hline & $\mathrm{N}$ & Min & Max & Mean & Std. Dev & Decision \\
\hline Institution & 10 & 1 & 1 & 1.00 & .000 & - \\
\hline Sex & 10 & 1 & 2 & 1.30 & .483 & - \\
\hline Qualification & 10 & 1 & 4 & 1.90 & 1.101 & - \\
\hline Working Experience & 10 & 1 & 2 & 1.20 & .422 & - \\
\hline Adequacy & 10 & 4 & 5 & 4.50 & .527 & Accepted \\
\hline Item 6 & 10 & 4 & 5 & 4.40 & .516 & Accepted \\
\hline Item 7 & 10 & 4 & 5 & 4.50 & .527 & Accepted \\
\hline Item 8 & 10 & 4 & 5 & 4.70 & .483 & Accepted \\
\hline Item 9 & 10 & 4 & 5 & 4.50 & .527 & Accepted \\
\hline Item 10 & 10 & 4 & 5 & 4.20 & .422 & Accepted \\
\hline Item 11 & 10 & 4 & 5 & 4.50 & .527 & Accepted \\
\hline Item 12 & 10 & 4 & 5 & 4.40 & .516 & Accepted \\
\hline Item 13 & 10 & 4 & 5 & 4.70 & .483 & Accepted \\
\hline Item 14 & 10 & 4 & 5 & 4.60 & .516 & Accepted \\
\hline Item 15 & 10 & 4 & 5 & 4.60 & .516 & Accepted \\
\hline Item 16 & 10 & 4 & 5 & 4.50 & .527 & Accepted \\
\hline Item 17 & 10 & 4 & 5 & 4.60 & .516 & Accepted \\
\hline Item 18 & 10 & 4 & 5 & 4.60 & .516 & Accepted \\
\hline Item 19 & 10 & 4 & 5 & 4.60 & .516 & Accepted \\
\hline Item 20 & 10 & 4 & 5 & 4.60 & .516 & Accepted \\
\hline Item 21 & 10 & 4 & 5 & 4.50 & .527 & Accepted \\
\hline Item 22 & 10 & 4 & 5 & 4.60 & .516 & Accepted \\
\hline Valid N (listwise) & 10 & & & & & \\
\hline
\end{tabular}

Item 7, corresponding to item 3 on the LORI rated the feedback and adaptation of the package or whether the feedback is driven by differential learner input or learner modeling. A mean score of 4.20 was obtained showing that respondents were satisfied with the fact that the package has the ability to tailor instructional messages or activities according to the specific needs or characteristics of the learner or to simulate or construct phenomena under study in response to differential input from the learner. A model or profile of the learner is maintained that influences the behavior of the learning object. 
Item 8 , corresponding to item 4 on the LORI rated the ability of the package to motivate and interest an identified population of learners. A mean score of 3.6 obtained is significant enough to indicate that the respondents were satisfied that the package is highly motivating. Its content is relevant to the personal goals and interests of the intended learners. The object offers choice, true-to-life learning activities, multimedia, interactivity, humor, drama, or game-like challenges. It provides realistic expectations and criteria for success. Feedback compares learner performance to the criteria, shows natural consequences of the performance, and explains how the performance can be improved. Learners are likely to report an increased interest in the topic after working with the learning object.

Item 9 , corresponding to item 5 on the LORI rated the design of visual and auditory information contained in the package for enhanced learning and efficient mental processing. A mean score of 3.80 obtained shows that the respondents were satisfied that the production values and information design enable the user to learn efficiently. The presentations minimize visual search. Text is legible. Animated or video recorded events are described by audio narration. Meaningful headings signal the content of text passages. Writing is clear, concise and free of errors. Color, music, and decorative features are aesthetically pleasing and do not interfere with learning goals.

Item 10 , corresponding to item 6 on the LORI rated the ease of navigation, predictability of the user interface and the level to which the quality of the interface help features of the package. The user interface design implicitly informs learners how to interact with the object, or there are clear instructions guiding use. Navigation through the object is easy, intuitive and free from excessive delay. The behavior of the user interface is consistent and predictable. A mean rating of 4.80 obtained shows that the respondents were highly satisfied that the user interface design implicitly informs learners how to interact with the object, or there are clear instructions guiding use. Navigation through the object is easy, intuitive and free from excessive delay. The behavior of the user interface is consistent and predictable.

Item 11 , corresponding to item 7 on the LORI rated the accessibility of the package that is, the level to which the design of the controls and presentation formats can accommodate disable and mobile learners. A mean rating of 4.60 obtained here shows that the respondents were satisfied the package provides a high degree of accommodation for learners with sensory and motor disabilities, and can be accessed through assistive and highly portable devices.

Item 12 , corresponding to item 8 on the LORI rated the reusability of the package, that is, the ability to use it in varying learning context and with learners from different backgrounds. A mean score of 4.80 obtained shows that the respondents were satisfied that the package is a stand-alone resource that can be readily transferred to different courses, learning designs and contexts without modification. It operates effectively with a broad range of learners by adapting content or providing adjunctive content such as glossaries and summaries of prerequisite concepts.

Finally, Item 13 corresponding to item 9 on the LORI rated the standard of compliance of the package to international standards and specifications. A mean rating of 3.2 slightly shows that respondents were satisfied that the package adheres to all relevant international standards and specifications. These include the IEEE 
Learning Object Metadata standards, and technical guidelines developed by IMS, IEEE, SCORM and W3C (accessibility guidelines not included). Sufficient standard metadata is provided in tagged code within the object and presented in a page available to users. Based on this analysis, almost all the respondents have rated the package high enough to enable the researchers to agree that the package have met required instructional technology standards. The analysis of the responses of 5 computer analysts was presented in Table 3.

Table 2. Responses of Instructional Technologists on the Conformity of the Package to Acceptable Standards of Instructional Development and Delivery

\begin{tabular}{lcccccc}
\hline & $\mathrm{N}$ & Min & Max & Mean & Std. Dev & Decision \\
\hline Institution & 5 & 2 & 3 & 2.80 & .447 & - \\
Gender & 5 & 1 & 2 & 1.20 & .447 & - \\
Qualification & 5 & 2 & 3 & 2.80 & .447 & - \\
Experience & 5 & 2 & 3 & 2.80 & .447 & - \\
Scores & 5 & 3 & 5 & 4.00 & .707 & Accepted \\
Item 6 & 5 & 3 & 5 & 3.80 & .837 & Accepted \\
Item 7 & 5 & 4 & 5 & 4.20 & .447 & Accepted \\
Item 8 & 5 & 3 & 4 & 3.60 & .548 & Accepted \\
Item 9 & 5 & 3 & 4 & 3.80 & .447 & Accepted \\
Item 10 & 5 & 4 & 5 & 4.80 & .447 & Accepted \\
Item 11 & 5 & 4 & 5 & 4.60 & .548 & Accepted \\
Item 12 & 5 & 4 & 5 & 4.80 & .447 & Accepted \\
Item 13 & 5 & 3 & 4 & 3.20 & .447 & Accepted \\
Valid N (listwise) & 5 & & & & & \\
\hline
\end{tabular}

Items 1 to 4 describes the personal data of the respondents, which indicates that 3 were from a University, while 2 were from a College of Education; $80 \%$ were male; their highest qualification was Master degree; and most of them have been working for between 1 to 10 years. With the exception of items 6 , 12 and 19 that has a mean score of 3.80 each, all the other descriptors has a mean score above 4.00 each. This shows that respondents were satisfied with the typography, legibility, navigation, and the simulation properties among others, of the instructional package. And in line with CIPP model of evaluation of instructional products. The CIPP is an acronym for Context, Input, Process and Product. The package can therefore be said to have met the required standard.

From the result and discussions, the following findings emerged (1) Proper Instructional Design procedures were followed in the development of EECOBTIP, (2) EECOBTIP have adequately covered the curriculum content of the subject matter, (3) EECOBTIP have met required instructional technology requirements, and EECOBTIP have met the required technical requirements. 
Table 3. Responses of Computer Experts on the Typography, Legibility, Navigation and the Simulation Properties among Others, of the Instructional Package

\begin{tabular}{lcccccc}
\hline & $\mathrm{N}$ & Min & Max & Mean & Std. Dev. & Decision \\
\hline Institution & 5 & 2 & 3 & 2.40 & .548 & - \\
Gender & 5 & 1 & 2 & 1.40 & .548 & - \\
Qualification & 5 & 2 & 2 & 2.00 & .000 & - \\
Experience & 5 & 2 & 4 & 3.20 & .837 & - \\
Descriptors & 5 & 3 & 5 & 4.00 & .707 & Accepted \\
Item 6 & 5 & 3 & 5 & 3.80 & .837 & Accepted \\
Item 7 & 5 & 3 & 5 & 4.00 & .707 & Accepted \\
Item 8 & 5 & 4 & 5 & 4.20 & .447 & Accepted \\
Item 9 & 5 & 3 & 5 & 4.20 & .837 & Accepted \\
Item 10 & 5 & 4 & 5 & 4.80 & .447 & Accepted \\
Item 11 & 5 & 3 & 5 & 4.00 & .707 & Accepted \\
Item 12 & 5 & 3 & 5 & 3.80 & .837 & Accepted \\
Item 13 & 5 & 4 & 5 & 4.40 & .548 & Accepted \\
Item 14 & 5 & 4 & 5 & 4.60 & .548 & Accepted \\
Item 15 & 5 & 3 & 5 & 4.00 & 1.000 & Accepted \\
Item 16 & 5 & 4 & 5 & 4.60 & .548 & Accepted \\
Item 17 & 5 & 4 & 5 & 4.80 & .447 & Accepted \\
Item 18 & 5 & 4 & 4 & 4.00 & .000 & Accepted \\
Item 19 & 5 & 3 & 5 & 3.80 & .837 & Accepted \\
Valid N & 5 & & & & & \\
\hline
\end{tabular}

\section{CONCLUSION}

The outcome of this study was the design and development of an electronic learning package that provides Basic Technology Teachers with an avenue for placing young learners in front of advanced communications technology so that they can retrieve data from a supposedly intelligent machine instead of interacting with other people. It also provides a means of easing the task of the teacher, in combining individual resources into instructionally meaningful lessons that is similar to the speaker's task of combining individual words and utterances into meaningful communication. The outcome of the study will therefore be of immense benefit to SUBEB, by identifying areas of difficulties in the teaching/learning of Basic Electronics. It will also be beneficial to teachers/learners by providing an electronic platform that will make teaching/learning easier. Basic Technology teachers should be encouraged to prepare some aspects of their lessons in electronic form. This will provide them with alternative ways of lesson presentation, and will equally give learners alternative learning approaches. EECOBTIP should be utilized for classroom instruction especially when teaching the Electricity/ Electronics component of Basic Technology.Similar packages should be developed for the other aspects of Basic Technology curriculum. The study should also be replicated in other areas of teaching and learning. 


\section{REFERENCES}

[1] R. D. Tennyson, "Historical Reflection on Learning Theories and Instructional Design," Contemp. Educ. Technol., vol. 1, no. 1, pp. 116, 2010.

[2] J. Dewey, How we think. Boston: D.C. Heath, 1910.

[3] E. L. Thorndike, The Psychology of Learning: Educational Psychology, 2nd ed. New York: Teachers College Press, 1913.

[4] B. F. Adeoye and O. S. Olabiyi, "Basic Technology Textbooks in Nigerian Secondary Schools: A Quality and Content Analysis, CICE Hiroshima University," J. Int. Coop. Educ., vol. 14, no. 2, pp. 153-168, 2011.

[5] Nigerian Educational Research and Development Council (NERDC), National Policy on Education. Federal Republic of Nigeria, 2004.

[6] V. O. Uwaifo and I. U. Uwaifo, "Training Technology and Vocational Education Teachers for the New 9-34 Education System in Nigeria: Its Problems and Prospects," Int. NGOJ., vol. 4, no. 4, pp. 160-166, 2009.

[7] A. J.Davidson, "Teaching and Learning Baseline Survey Summary Report," 2013.

[8] A. D.Olaniyan and B. L. Ojo, "Challenges against Implementation of Introductory Technology Curriculum in Nigerian Junior Secondary Schools," Eur. J. Sci. Res., vol. 24, pp. 112-118, 2008.

[9] R. Koper, "Modeling Units of Study from A Pedagogical Perspective the Pedagogical Meta-Model behind EML," Heerlen, 2001.

[10] P. Goodyear, "Effective Networked Learning in Higher Education: Notes and Guidelines," Lancaster, 2001.

[11] A. Earle, "Designing For Pedagogical Flexibility: Experiences From the CANDLE Project," J. Interact. Media Educ., vol. 2002, no. 1, p. 4, Jul. 2002.
[12] S. Britain and O. Liber, "A Framework for Pedagogical Evaluation of Virtual Learning Environments (Revised)," 2004.

[13] H. Beetham, "Developing Learning Technology Networks through Shared Representations of Practice," in Proceedings of the 9th International Improving Student Learning Symposium, 2002, pp. 421-434.

[14] S. Shurville and T. Browne, "Introduction: ICT-driven change in higher education: Learning from elearning," J. Organ. Transform. Soc. Chang., vol. 3, no. 3, pp. 245-250, Jul. 2007.

[15] J. Schreurs and R. Dumbraveanu, "A Shift from Teacher Centered to Learner Centered Approach," Int. J. Eng. Pedagog., vol. 4, no. 3, p. 36, Jun. 2014.

[16] E. Boyadzhieva, "Learner-centered Teaching and Learner Autonomy," Procedia - Soc. Behav. Sci., vol. 232, pp. 35-40, Oct. 2016.

[17] M. Treadwell, The Paradigm Shift. New Zealand: Global, 2013.

[18] P. Budiastuti, M. Khairudin, and M. N. Azman, "E-Instructional Multimedia in Basic Concepts of Electrical and Electronic Lessons," $J$. Pendidik. Teknol. dan Kejuru., vol. 24, no. 2, pp. 262-269, Sep. 2018.

[19] S. Packer, P. Elumeze, and M. B. Shitu, "State Education Sector Project: Institutional Assessment Kano State," 2006.

[20] M. Salihu, "Kano State Revised Education Strategic Plan, 20092018," Kano State, 2008.

[21] J. D. Finn, "Automation and Education: General Aspects," $A V$ Commun. Rev., vol. 5, pp. 343-360, 1957.

[22] R. Rita C., "Developmental Research: The Definition and Scope," in The 1994 National Convention of the Association for Educational Communications and Technology, 1994. 
[23] S. McKenney, "Computer-based Support for Science Education Materials Development in Africa: Exploring Potentials," Universiteit Twente, 2001.

[24] L. F. Johnson, "Elusive Vision:Challenges Impeding the Learning Object Economy," San Francisco, 2003.

[25] R. S. Smith, "Guidelines for Authors of Learning Objects," 2004.

[26] A. Crossman, "Understanding Purposive Sampling," 2019.
[27] Nigerian Educational Research and Development Council (NERDC), "9Year Basic Education Curriculum: Basic Technology for JSS 1 - 3," Abuja, Nigeria, 2007.

[28] J. Vargo, C. J. Nesbit, J. Belfer, and A. Archambault, "Learning Object Evaluation: Computer mediated Collaboration and Inter-Rater Reliability," Int. J. Comput. Appl., vol. 25, no. 3, pp. 198-205, 2013. 